\title{
Perfil de ácidos graxos da gordura intramuscular da carne de vacas de descarte de diferentes grupos genéticos terminadas em confinamento, abatidas com distintos pesos
}

\author{
Fatty acid profile intramuscular fat meat of cull cows from different genetic groups feedlot finished \\ slaughtered with distinct weights
}

\author{
Fernando Kuss $^{\text {I* }}$ João Restle ${ }^{\text {II }}$ Gilberto Vilmar Kosloski ${ }^{I I I}$ Francisco Deschamps $^{\text {IV }}$ \\ José Luis MolettaV Angélica Pereira dos Santos $^{\mathrm{I}}$ Jarlei Fiamoncini $^{\mathrm{VI}}$
}

\section{RESUMO}

Foi avaliado o perfil dos ácidos graxos da gordura intramuscular do Longissimus dorsi de vacas de descarte mestiças, da segunda (G2 - 3/4Charolês (C) 1/4Nelore (N) e 3/ $4 N C)$ e da terceira geração (G3 - 5/8CN e 5/8NC) de cruzamento rotativo Charolês - Nelore, terminadas em confinamento e abatidas com 465, 507 ou 566kg. Os animais apresentaram, na média, no início do confinamento, 8,5 anos, $388,6 \mathrm{~kg} e$ 2,35 pontos de escore da condição corporal. A dieta alimentar, relação volumoso:concentrado de 48:52, continha 12,5\% de proteína bruta e 2,99Mcal de energia digestível por $\mathrm{kg}$ de matéria seca. Os ácidos graxos saturados C14:0 (merístico) e C16:0 (palmítico) reduziram as suas participações em 19 e $10 \%$, respectivamente, com o aumento do peso de abate de 465 para $566 \mathrm{~kg}$, mesmo comportamento observado para o $\mathrm{C}$ 18:0 (esteárico). Houve menor representação dos ácidos saturados em detrimento aos insaturados com o incremento do peso de abate, sendo a associação negativa ( $r=-0,61$; $P<0,01$ ) entre o marmoreio e a fração de gordura saturada na gordura intramuscular do músculo Longissimus dorsi. A carne das vacas 3/4NC apresentou maior fração dos ácidos graxos palmítico e palmitiléico. Houve redução da participação do ácido graxo pentadecanóico e palmitiléico, e incremento da fração do ácido graxo esteárico da G2 para a G3. O aumento do peso de abate de vacas de descarte propicia um perfil de ácido graxo da gordura intramuscular do Longissimus dorsi benéfico à saúde humana por reduzir a participação de ácidos graxos hipercolesterolêmicos e aumentar os hipocolesterolêmicos. Vacas 3/4 Nelore 1/4 Charolês apresentam maior fração de ácido graxo palmítico e palmitiléico, enquanto que as 5/8 Charolês 3/8 Nelore demonstram maior concentração de esteárico. Animais da terceira geração do cruzamento alternado Charolês - Nelore apresentam carne com menor concentração do ácido graxo palmitiléico e maior de esteárico.

Palavras-chave: Charolês, composição lipídica, cruzamento,
fêmeas, gordura insaturada, Nelore.

\section{ABSTRACT}

The Longissimus dorsi marbling fatty acid profile of crossbred cull cows, from the second (G2-3/4Charolais (C) Nellore (N) and 3/4NC) and third (G3 - 5/8CN and 5/8NC) generation of Charolais - Nellore rotational crossbreeding, feedlot finished and slaughtered with 465, 507 and $566 \mathrm{~kg}$ were evaluate. At the beginning of the experiment the average age, weight and body condition were, respectively, 8.5 years, $388.6 \mathrm{~kg}$ and 2.35 points. The diet, with 48:52 roughage:concentrate ratio, contained $12.5 \%$ crude protein and $2.99 \mathrm{Mcal}$ of digestible energy per $\mathrm{kg}$ of dry matter. The fatty acids saturated C14:0 (myristic) and C16:0 (palmitic) reduce the his participations in 19 and $10 \%$, respectively, with the amplification of the weight of slaughter of 465 about to $566 \mathrm{~kg}$, even behavior observer about to the C18:0 (stearic). There was minor representation of the acids saturated detriment insaturad with the increase of the weight of slaughter, being the association negative $(r=-0.61 ; P=.01)$ among the marbling and the fraction of fat saturated on fat intramuscular of the muscle Longissimus dorsi. The meat from the culls 3/4NC presented major fraction from the fatty acids palmitic and palmitic-oleico. These was reduction of the participation of the fatty acid pentadecanoic and palmitic-oleico, and increase of the fraction of the fatty acid stearic from G2 about to G3. The increase of the weight of culls cows appease a profile of fatty acid from fat intramuscular of the Longissimus dorsi beneficial on the health human reducing the participation of fatty acids

IPrograma de Pós-graduação em Zootecnia, Universidade Federal do Rio Grande do Sul (UFRGS). Porto Alegre, RS, Brasil. E-mail: fernandokuss@gmail.com. Autor para correspondência.

IIDepartamento de Produção Animal, Escola de Veterinária da Universidade Federal de Goiás (UFG). Goiás, Goiânia, Brasil.

IIIDepartamento de Zootecnia, UFSM. Santa Maria, RS, Brasil.

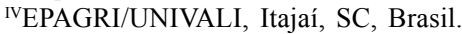

VInstituto Agronômico do Paraná (IAPAR), Londrina, PR, Brasil.

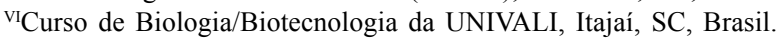


hipercolesterolemics and increase the hipocolesterolemics. The culls cows 3/4Charolês 1/4Nelore they presented high fraction of fatty acid palmitic and palmitic-oleico, while the 5/8Charolês 3/8Nelore presented demonstrate high concentration of stearic. Animals from third generation of the Charolais - Nellore rotational crossbreeding, presented meat with low concentration of the fatty acid palmitic-oleico and high of stearic.

Key words: Charolais, composition fat, crossbreeding, cull females, insatured fat, Nellore.

\section{INTRODUÇÃO}

Recentemente, além do teor de gordura, a avaliação do perfil de ácidos presentes na carne tem despertado interesse da comunidade científica, principalmente de pesquisadores da área de nutrição e melhoramento genético animal, visando a estabelecer dietas e genótipos que propiciem um produto final de melhor qualidade e benéfico à saúde humana. Embora a mídia divulgue que normalmente a ingestão de gordura animal esteja associada a doenças cardiovasculares e cancerígenas, estudos têm demonstrado que o consumo moderado dessa gordura pode prevenir o desenvolvimento dessas mesmas doenças. Alguns ácidos graxos, particularmente os polinsaturados, servem como matéria-prima para substâncias que regulam a imunidade, a coagulação sanguínea, a contração dos vasos e a pressão arterial (SIMOPOULOS, 1999).

Os diferentes bioclimas existentes no território brasileiro, de tropical a subtropical, condicionam os distintos sistemas de produção de bovinos de corte em razão da adaptabilidade das raças para com estes meios. Trabalhos de pesquisas demonstram que o cruzamento de raças Bos taurus Bos indicus tem sido uma alternativa viável ao produtor para melhorar a qualidade da carne (maciez, suculência e palatabilidade) de vacas de descarte (RESTLE et al., 2002; RESTLE et al., 2003; KUSS et al., 2005). No entanto, ainda são poucos os estudos que avaliam a composição dos ácidos graxos da carne de fêmeas bovinas de diferentes grupos genéticos (HUERTALEINDENZ et al., 1993; ZEMBAYASHI et al., 1995; MALAU-ADULI et al., 1998). No estudo de HUERTALEINDENZ et al. (1993), ficou demonstrado que vacas Bos taurus (Hereford) apresentaram maior proporção de ácidos graxos saturados e menor de polinsaturados que vacas Bos indicus (Brahman).

Considera-se que, no Brasil, aproximadamente $50 \%$ dos animais abatidos são fêmeas (ANUALPEC, 2005). No trabalho de KUSS et al. (2005), ficou demonstrado que o incremento do peso de abate de vacas de descarte resulta no aumento da produção de carne e melhora da maciez. Porém, é necessário gerar informações mais detalhadas relacionadas aos aspectos qualitativos da carne desta categoria. Neste contexto, esta pesquisa foi conduzida com o intuito de avaliar o perfil de ácidos graxos e a qualidade da carne de vacas de descarte, mestiças Charolês-Nelore, terminadas em confinamento e abatidas com diferentes pesos.

\section{MATERIAL E MÉTODOS}

O estudo foi conduzido no Setor de Bovinocultura de Corte do Departamento de Zootecnia da Universidade Federal de Santa Maria (UFSM). Para este estudo, foram utilizadas 24 vacas de descarte mestiças Charolês x Nelore, sendo 12 animais da segunda (G2) (seis vacas 3/4C-1/4N e seis vacas $3 / 4 \mathrm{~N}$ $1 / 4 \mathrm{C}$ ) e 12 da terceira geração (G3) (seis vacas 5/8C-3/ $8 \mathrm{~N}$ e seis vacas $5 / 8 \mathrm{~N}-3 / 8 \mathrm{C}$ ). Ao início do período experimental, apresentavam, em média, 8,5 anos de idade, $388,6 \mathrm{~kg}$ de peso vivo e 2,35 pontos de escore da condição corporal (escala de 1 a 5). A dieta continha $12,5 \%$ de proteína bruta e 2,99 Mcal de energia digestível $\mathrm{kg}^{-1}$ de matéria seca (MS), composta de $48 \%$ de volumoso (silagem de milho) e $52 \%$ de concentrado (92\% de farelo de trigo; $6,8 \%$ de calcário calcítico e $0,6 \%$ de sal comum, com base na MS).

Os tratamentos consistiram de três faixas de peso de abate. Os pesos de abate inicialmente propostos eram de 460,510 e $560 \mathrm{~kg}$, sendo os pesos reais 465 (T465), 507 (T507) e 566kg (T566); 3,15; 3,45 e 4,56 pontos de escore de condição corporal ao abate; totalizando 60, 75 e 140 dias de terminação em confinamento, respectivamente. Os animais foram abatidos em frigorífico comercial, obedecendo ao fluxo de abate normal do estabelecimento. Por ocasião do abate, as carcaças foram identificadas e mantidas em câmara fria por um período de $24 \mathrm{~h}$, à temperatura de $0^{\circ} \mathrm{C}$. Decorrido este período, para a aferição do perfil de ácidos graxos, foi extraída uma amostra na meia carcaça direita, do músculo Longissimus dorsi, correspondendo à porção da 10-11-12 ${ }^{\mathrm{a}}$ costelas, a qual foi embalada em lâmina de plástico e papel pardo, identificada e imediatamente congelada à temperatura de $-18^{\circ} \mathrm{C}$, durante 60 dias. Após este período, foi retirado um bife, o qual foi secada em estufa de ventilação forçada $\left(55^{\circ} \mathrm{C}\right)$ e moído (peneira de $1 \mathrm{~mm}$ ) para a extração dos lipídeos, utilizando-se o método modificado de FOLCH et al. (1957).

Cerca de $0,5 \mathrm{~g}$ de cada amostra foram colocados em um tubo de vidro e adicionados $10 \mathrm{~mL}$ de clorofórmio/metanol (2:1). Após 24 horas, foram adicionados $10 \mathrm{~mL}$ de água destilada e os tubos 
centrifugados a $500 \times \mathrm{g}$, por 5 minutos, para separar as fases. Transferiu-se a fase orgânica (clorofórmio) para tubos de ensaio com tampa rosqueável, sendo deixada em banho-maria a $40^{\circ} \mathrm{C}$, sob fluxo de ar comprimido, até restarem apenas os lipídios no fundo do tubo.

Para derivatização dos ácidos graxos, foram adicionados no tubo com os lipídeos $500 \mathrm{~mL}$ de $\mathrm{KOH}$ $0,4 \mathrm{M}$ em metanol, deixando-se em banho-maria $\left(60^{\circ} \mathrm{C}\right.$, por duas horas). Posteriormente, após resfriados sob temperatura ambiente, foram adicionados $1,5 \mathrm{~mL}$ de $\mathrm{H}_{2} \mathrm{SO}_{4}(1 \mathrm{M})$ em metanol. Os tubos foram deixados novamente em banho-maria a $60^{\circ} \mathrm{C}$, por mais duas horas. A seguir, foram resfriados e adicionados $2 \mathrm{~mL}$ de $n$ hexano para recuperar os derivados. Os ésteres metílicos de ácidos graxos foram mantidos a $-18^{\circ} \mathrm{C}$ até o momento de sua análise.

A determinação foi feita em cromatógrafo a gás, equipado com o detector de ionização de chama (FID) e coluna capilar Supelco SP2340 (60 m x 0,25mm x $0,2 \mu \mathrm{m})$. As temperaturas do detector e injetor foram $260^{\circ} \mathrm{C}$ e $240^{\circ} \mathrm{C}$, respectivamente. A programação de aquecimento da coluna foi iniciada com $140^{\circ} \mathrm{C}$ por 5 minutos, havendo aumento gradual de $4^{\circ} \mathrm{C}$ por min até a temperatura final de $240^{\circ} \mathrm{C}$, permanecendo assim por $5 \mathrm{~min}$. $\mathrm{O}$ fluxo de gás de arraste $\left(\mathrm{H}_{2}\right)$ foi de $17 \mathrm{~mL} \mathrm{~min}^{-1}$. O volume de injeção foi de $0,5 \mu \mathrm{L}$, com razão de split de 1:100. A identificação dos picos, assim como a quantificação, foram feitas pela comparação dos tempos de retenção e da área dos picos das amostras com as de padrões de ésteres metílicos de ácidos graxos (Supelco 37 components FAMEs Mix, ref. 47885-U).

O delineamento experimental utilizado foi o inteiramente casualizado com arranjo fatorial $3 \times 2 \times 2$ ( 3 pesos de abate $\mathrm{x} 2$ gerações de cruzamento $\mathrm{x} 2$ grupos genéticos aninhados dentro de cada geração de cruzamento), sendo os dados submetidos à análise de normalidade, pelo teste Shaphiro-wilk, e de variância pelo teste $\mathrm{F}$.

As interações de peso de abate e geração de cruzamento e com grupo genético dentro de geração foram inicialmente testadas e removidas do modelo estatístico final, pois não foram significativas para as variáveis avaliadas. As médias das variáveis dependentes significativamente afetadas pelas variáveis independentes, segundo análise de variância, foram comparadas através do teste da probabilidade da diferença (pdiff), com nível de significância de 10\%, utilizando-se o pacote estatístico SAS (1997).

\section{RESULTADOS E DISCUSSÃO}

A composição lipídica da gordura intramuscular da carne de vacas de descarte abatidas com diferentes pesos está descrita na tabela 1. Observase que os ácidos graxos saturados C14:0 (merístico) e

Tabela 1 - Perfil (\%) dos ácidos graxos do músculo Longissimus dorsi de vacas de descarte terminadas em confinamento, de acordo com o peso de abate.

\begin{tabular}{|c|c|c|c|c|c|}
\hline \multirow{2}{*}{ Ácidos graxos } & \multicolumn{3}{|c|}{ Peso de abate, $\mathrm{kg}$ de peso vivo } & \multirow{2}{*}{$\mathrm{EP}^{1}$} & \multirow{2}{*}{$\mathrm{P}^{2}$} \\
\hline & 465 & 507 & 566 & & \\
\hline C14:0 (Mirístico) & $3,50 \mathrm{a}$ & $2.92 b$ & $2,83 b$ & 0.18 & $* *$ \\
\hline C14:1 (Meristoléico) & $0,44 \mathrm{a}$ & $0,31 b$ & $0,46 \mathrm{a}$ & 0,04 & $* *$ \\
\hline C15:0 (Pentadecanóico) & $0,30 \mathrm{a}$ & $0,17 \mathrm{~b}$ & $0,21 b$ & 0,04 & $*$ \\
\hline C16:0 (Palmítico) & $32,62 \mathrm{a}$ & $30,66 b$ & $29,33 b$ & 0,70 & $*$ \\
\hline C16:1 (Palmitoléico) & $2,90 \mathrm{~b}$ & $2,76 b$ & $3,15 \mathrm{a}$ & 0,10 & $*$ \\
\hline C17:0 (Heptadecanóico) & $1,04 \mathrm{a}$ & $0,96 \mathrm{ab}$ & $0,87 \mathrm{~b}$ & 0,05 & $* *$ \\
\hline C17:1 (Cis-10-Heptadecanóico) & 0,49 & 0,46 & 0,51 & 0,03 & Ns \\
\hline C18:0 (Esteárico) & $19,69 \mathrm{a}$ & $20,54 a$ & $17,95 b$ & 0,61 & $*$ \\
\hline C18:1 n9t (Elaídico) & 0,92 & 0,50 & 0,35 & 0,25 & Ns \\
\hline C18:1 n9c (Oléico) & $36,30 \mathrm{c}$ & $39,07 b$ & $42,44 \mathrm{a}$ & 0,92 & $* *$ \\
\hline C18:2 n6c (Linoléico) & $1,37 \mathrm{ab}$ & $1,26 \mathrm{~b}$ & $1,60 \mathrm{a}$ & 0,11 & $* *$ \\
\hline C20:4 n6 (Araquidôneo) & 0,42 & 0,37 & 0,32 & 0,05 & Ns \\
\hline Saturados & $57,15 \mathrm{a}$ & $55,26 \mathrm{~b}$ & $51,20 \mathrm{c}$ & 0,72 & $*$ \\
\hline Insaturados & $42,85 \mathrm{c}$ & $44,75 b$ & $48,84 \mathrm{a}$ & 0,72 & $*$ \\
\hline Monoinsaturados & $41,05 \mathrm{c}$ & $43,11 b$ & $46,91 \mathrm{a}$ & 0,76 & $*$ \\
\hline Poliinsaturados & 1,80 & 1,64 & 1,92 & 0,15 & ns \\
\hline Poliinsaturado: saturado & $0,031 \mathrm{ab}$ & $0,029 b$ & $0,037 \mathrm{a}$ & 0,003 & $* *$ \\
\hline
\end{tabular}

${ }^{1}$ Erro padrão das médias, sendo $\mathrm{n}=8$ por tratamento.

${ }^{2}$ Probabilidade, * $(\mathrm{P}<0,10), * *(\mathrm{P}<0,05)$ e ns (não-significativo). 
C16:0 (palmítico) reduziram as suas participações em 19 e $10 \%$, respectivamente, com o aumento do peso de abate de 465 para 566kg. Estes resultados são diferentes dos observados por XIE et al. (1996), que encontraram valores estáveis destes isômeros na gordura intramuscular de novilhos cruzas Wagyu, quando abatidos entre 649 e 725kg. Segundo DIETSCHY (1998), estes ácidos graxos são considerados hipercolesterolêmicos, devido ao fato de estes isômeros demonstrarem menor ação sobre a atividade dos receptores hepáticos para a lipoproteína de baixa densidade (LDL), ou o mau colesterol, aumentando assim a LDL circulante no plasma sangüíneo.

Outro ácido graxo saturado com relevante participação na gordura dos bovinos, o 18:0 (esteárico), em nosso estudo, demonstrou menor participação no T566. Embora este isômero represente em torno de 20\% da gordura intramuscular, ele é considerado neutro quanto a sua ação sobre as LDL circulantes (DIETSCHY, 1998). No estudo de XIE et al. (1996), os valores médios foram inferiores aos observados no presente estudo, porém demonstram mesma tendência de reduzir sua participação na gordura intramuscular com o aumento do peso de abate. Já WALDMAN et al. (1968), abatendo novilhos aos 386, 420 e 454 kg, não verificaram diferença significativa entre os tratamento (média de 17,04\%), porém a correlação entre peso de carcaça e ácido graxo esteárico foi negativa e significativa $(-0,33 ; \mathrm{P}<0,05)$. MACEDO et al. (2005), analisando o perfil de ácidos graxos no contrafilé de novilhas mestiças, encontraram valores inferiores aos do presente estudo (média de 16,34\%). Já NOCI et al. (2005), trabalhando com novilhas Charolês em períodos crescentes de terminação em pastagem de azevém $(0,40$, 99 e 158 dias), reportam valores similares aos deste estudo para o ácido graxo esteário entre os tratamentos (média de $18,56 \%$ ). No entanto, os animais não apresentaram diferença entre os tratamento quanto ao peso de abate. Observa-se que os resultados da literatura quanto à participação do ácido graxo esteárico são contraditórios, não havendo explicação para estes fatos, sendo necessários mais estudos sobre o perfil de ácidos graxos quanto ao grau de acabamento.

Quanto aos ácidos graxos monoinsaturados considerados hipercolesterolêmicos, destacam-se em nosso estudo os ácidos graxos C14:1 (meristoléico), que se manteve estável entre os pesos de abate extremos; e o C16:1 (palmitoléico), que demonstrou aumentar sua participação com o incremento do peso de abate. XIE et al. (1996) demonstram, para ambos os ácidos graxos, maior representação com o incremento do peso de abate de novilhos. No entanto, entre os monoinsaturados, deve-se destacar o oléico (C18:1 n9cis), considerado na literatura científica com propriedades hipocolesterolêmicas (DIETSCHY, 1998), o qual demonstrou ser mais representativo com o avanço do peso de abate. A associação entre a quantidade de gordura intramuscular (de marmorização) e o ácido oléico foram positivas $(\mathrm{r}=0,54 ; \mathrm{P}<0,01)$. Similar comportamento também foi observado no estudo de XIE et al. (1996).

Ainda na tabela 1, verifica-se que houve menor representação dos ácidos saturados em detrimento dos insaturados com o incremento do peso de abate, isso devido principalmente às reduções dos ácidos merístico, palmítico e esteárico, e aumento do ácido oléico. Em nosso estudo, a correlação se mostrou negativa $(\mathrm{r}=-0,61 ; \mathrm{P}<0,01)$ entre o marmoreio e a participação de gordura saturada, demonstrando que o aumento do grau de marmorização da carne, com o concomitante incremento do peso de abate, aumenta a fração de gordura insaturada.

$\mathrm{Na}$ tabela 2, são demonstrados os resultados obtidos segundo o grupo genético das vacas de descarte. Observa-se que a gordura intramuscular das vacas com maior composição genética Bos indicus (3/4NC) apresentou maior fração dos ácidos graxos palmítico e palmitiléico. No estudo de HUERTA-LEIDENZ et al. (1993), os autores verificaram, no tecido adiposo subcutâneo das vacas Brahman, valor inferior de ácido graxo palmítico e similar de ácido graxo palmitoléico, em comparação as vacas Hereford. Quanto ao ácido graxo esteárico, uma participação superior foi registrada na gordura intramuscular da carne das vacas $5 / 8 \mathrm{CN}$.

$\mathrm{Na}$ comparação entre as gerações de cruzamento (tabela 3), o aumento da heterozigose, de $50 \%$ na G2 para $75 \%$ na G3, resultou na redução da participação do ácido graxo pentadecanóico e palmitoléico, e incremento da fração do ácido graxo esteárico. No trabalho de PITCHFORD et al. (2002), quanto à herdabilidade genética para os ácidos graxos palmitiléico e esteárico, os autores demonstraram valores considerados moderados (16 e $14 \%$, respectivamente). Desta maneira, pode-se considerar que a carne das vacas da G3 é menos prejudicial à saúde humana por apresentar menor teor de palmitoléico, que é considerado hipercolestolemico, embora tenha apresentado maior concentração de esteárico, o qual é considerado neutro quanto a sua ação sobre as LDL circulantes (DIETSCHY, 1998).

\section{CONCLUSÕES}

O aumento do peso de abate de vacas de descarte propicia um perfil de ácido graxo da gordura 
Tabela 2 - Perfil (\%) dos ácidos graxos do músculo Longissimus dorsi de vacas de descarte terminadas em confinamento, de acordo com o grupo genético.

\begin{tabular}{|c|c|c|c|c|c|c|}
\hline \multirow{2}{*}{ Ácidos graxos } & \multicolumn{4}{|c|}{ Grupo genético } & \multirow{2}{*}{$\mathrm{EP}^{1}$} & \multirow{2}{*}{$\mathrm{P}^{2}$} \\
\hline & $3 / 4 \mathrm{CN}$ & $3 / 4 \mathrm{NC}$ & $5 / 8 \mathrm{CN}$ & $5 / 8 \mathrm{NC}$ & & \\
\hline C14:0 (Mirístico) & 2,95 & 3,38 & 2,92 & 3,08 & 0,21 & ns \\
\hline C14:1 (Meristoléico) & 0,38 & 0,40 & 0,37 & 0,47 & 0,05 & ns \\
\hline C15:0 (Pentadecanóico) & 0,28 & 0,27 & 0,17 & 0,20 & 0,05 & ns \\
\hline C16:0 (Palmítico) & $30,72 \mathrm{ab}$ & $32,33 a$ & $30,17 b$ & $30,28 b$ & 0,77 & $*$ \\
\hline C16:1 (Palmitoléico) & $3,02 \mathrm{ab}$ & $3,08 \mathrm{a}$ & $2,78 b$ & $2,87 \mathrm{ab}$ & 0,11 & $*$ \\
\hline C17:0 (Heptadecanóico) & 1,00 & 0,90 & 0,98 & 0,95 & 0,06 & ns \\
\hline C17:1 (Cis-10-Heptadecanóico) & 0,52 & 0,48 & 0,45 & 0,50 & 0,03 & ns \\
\hline C18:0 (Esteárico) & $18,67 \mathrm{~b}$ & $18,58 \mathrm{~b}$ & $20,77 \mathrm{a}$ & $19,55 \mathrm{ab}$ & 0,64 & $* *$ \\
\hline C18:1 n9t (Elaídico) & 0,87 & 0,37 & 0,65 & 0,48 & 0,30 & ns \\
\hline C18:1 n9c (Oléico) & 39,75 & 38,42 & 38,88 & 40,03 & 1,10 & ns \\
\hline C18:2 n6c (Linoléico) & 1,42 & 1,43 & 1,52 & 1,28 & 0,13 & ns \\
\hline C20:4 n6 (Araquidôneo) & 0,42 & 0,38 & 0,40 & 0,30 & 0,06 & ns \\
\hline Saturados & 53,62 & 55,47 & 55,00 & 54,07 & 0,83 & ns \\
\hline Insaturados & 46,37 & 44,56 & 45,05 & 45,93 & 0,83 & ns \\
\hline Monoinsaturados & 44,53 & 42,75 & 43,13 & 44,35 & 0,88 & ns \\
\hline Poliinsaturados & 1,83 & 1,82 & 1,92 & 1,58 & 0,17 & ns \\
\hline Poliinsaturado: Saturado & 0,87 & 0,81 & 0,82 & 0,85 & 0,03 & ns \\
\hline
\end{tabular}

${ }^{1}$ Erro padrão das médias, sendo $\mathrm{n}=6$ por tratamento.

${ }^{2}$ Probabilidade, * $(\mathrm{P}<0,10), * *(\mathrm{P}<0,05)$ e ns (não-significativo)

Tabela 3 - Perfil (\%) dos ácidos graxos do músculo Longissihus dorsi de vacas de descarte terminadas em confinamento, de acordo com a geração de cruzamento.

\begin{tabular}{|c|c|c|c|c|}
\hline \multirow{2}{*}{ Ácidos graxos } & \multicolumn{2}{|c|}{$\begin{array}{l}\text { Geração de } \\
\text { cruzamento }\end{array}$} & \multirow{2}{*}{$\mathrm{EP}^{1}$} & \multirow{2}{*}{$\mathrm{P}^{2}$} \\
\hline & $\mathrm{G} 2$ & G3 & & \\
\hline C14:0 (Mirístico) & 3,17 & 3,00 & 0,15 & ns \\
\hline C14:1 (Meristoléico) & 0,39 & 0,42 & 0,03 & ns \\
\hline C15:0 (Pentadecanóico) & 0,27 & 0,18 & 0,03 & $*$ \\
\hline C16:0 (Palmítico) & 31,52 & 30,22 & 0,54 & ns \\
\hline C16:1 (Palmitoléico) & 3,05 & 2,82 & 0,07 & $* *$ \\
\hline C17:0 (Heptadecanóico) & 0,95 & 0,97 & 0,04 & ns \\
\hline C17:1 (Cis-10-Heptadecanóico) & 0,50 & 0,47 & 0,02 & ns \\
\hline C18:0 (Esteárico) & 18,62 & 20,16 & 0,45 & $* *$ \\
\hline C18:1 n9t (Elaídico) & 0,62 & 0,57 & 0,21 & ns \\
\hline C18:1 n9c (Oléico) & 39,09 & 39,46 & 0,77 & ns \\
\hline C18:2 n6c (Linoléico) & 1,42 & 1,40 & 0,09 & ns \\
\hline C20:4 n6 (Araquidôneo) & 0,40 & 0,35 & 0,04 & ns \\
\hline Saturados & 54,54 & 54,53 & 0,60 & ns \\
\hline Insaturados & 45,46 & 45,47 & 0,60 & ns \\
\hline Monoinsaturados & 43,64 & 43,74 & 0,64 & ns \\
\hline Poliinsaturados & 1,82 & 1,75 & 0,12 & ns \\
\hline Poliinsaturado: Saturado & 0,84 & 0,84 & 0,02 & ns \\
\hline
\end{tabular}

${ }^{1}$ Erro padrão das médias, sendo $\mathrm{n}=12$ por tratamento.

${ }^{2}$ Probabilidade, $*(\mathrm{P}<0,10), * *(\mathrm{P}<0,05)$ e ns (não-significativo). intramuscular do Longissimus dorsi não-prejudicial à saúde humana por reduzir a participação de ácidos graxos hipercolesterolêmicos e aumentar os hipocolesterolêmicos.

Vacas 3/4 Nelore 1/4Charolês apresentaram maior fração de ácido graxo palmítico e palmitoléico, enquanto que as $5 / 8$ Charolês $3 / 4$ Nelore apresentaram maior concentração de esteárico. Animais da terceira geração do cruzamento alternado Charolês - Nelore apresentam carne com menor concentração do ácido graxo hipercolesterolêmico palmitoléico e maior do ácido graxo esteárico, o qual não tem ação sobre as LDL circulantes.

\section{AGRADECIMENTOS}

Ao Conselho Nacional de Desenvolvimento Científico e Tecnológico $(\mathrm{CNPq})$, pela concessão de bolsas de estudo aos alunos de pós-graduação.

\section{REFERÊNCIAS}

ANUALPEC. Anuário estatístico da produção animal. FNP ${ }^{\circledR}$ Consultoria \& Comércio. São Paulo: Camargo Soares, 2005. 400p.

Ciência Rural, v.37, n.3, mai-jun, 2007. 
DIETSCHY, J.M. Dietary fatty acids and the regulation of plasma low density lipoprotein cholesterol. Journal Nutrition, v.128, p.444-448, 1998.

FOLCH, J. et al. A simple method for the isolation and purification of total lipids from animal tissues. Journal Biological Chemical, v.226, p.497-509, 1957.

HUERTA-LEIDENZ, N.O. et al. Comparison of the fatty acid composition of subcutaneous adipose tissue from mature Brahman and Hereford cows. Journal of Animal Science, v.71, p.625-630, 1993.

KUSS, et al. Composição física da carcaça e qualidade da carne de vacas de descarte de diferentes grupos genéticos terminadas em confinamento com distintos pesos. Revista Brasileira de Zootecnia, v.34, n.4, p.1285-1296, 2005.

MACEDO, L.M.A.A. et al. Perfil de ácidos graxos de cinco cortes comerciais de novilhas mestiças $(1 / 2$ nelore $\mathrm{x} 1 / 2$ charoles) vazias ou prenhes. In.: REUNIÃO ANUAL DA SOCIEDADE BRASILEIRA DE ZOOTECNIA, 42, 2005, Goiânia-GO. Anais... Goiânia: SBZ, 2005. CDrom (Ruminantes).

MALAU-ADULI, A.E.O. et al. A comparison of the fatty acid composition of triacylglycerols in adipose tissue from Limousin and Jersey cattle. Australasian Journal Agricultural Research, v.48, p.715-722, 1998.

NOCI, F. et al. The fatty acid composition of muscle fat and subcutaneous adipose tissue of pasture-fed beef heifers: influence of the duration of grazing. Journal of Animal Science, v.83, p.1167-1178, 2005
PITCHFORD, W.S. et al. Genetic variation in fatness and acid composition of crossbred cattle. Journal of Animal Science, v.80, p.2825-2832, 2002.

RESTLE, J. et al. Características de carcaça e da carne de vacas de descarte de diferentes genótipos Charolês x Nelore, terminadas em confinamento. Ciência Rural, v.33, n.2, p.345-350, 2003.

RESTLE, J. et al. Efeito do grupo genético e da heterose na composição física e nas características qualitativas da carcaça e da carne de vacas de descarte terminadas em confinamento. Revista Brasileira de Zootecnia, v.31, n.3, p.1378-1387, 2002.

SAS INSTITUTE. SAS/STAT user's guide: statistics. 8.ed. Verson 6.11. Cary: 1997. V.6, 943p.

SIMOPOULOS, A.P. Essential fatty acids in health and chronic disease. American Journal Clinic and Nutrition, v.70, Suppl., p.560-569, 1999.

WALDMAN, R.C. et al. Fatty acids of certain bovine tissue and their association with growth, carcass and palatability traits. Journal of Animal Science, v.27, p.632-635, 1968.

XIE, Y.R. et al. Effects of time on feed and post-mortem aging on palatability and lipid composition of crossbred Wagyu beef. Meat Science. v.43, n.2, p.157-166, 1996.

ZEMBAYASHI, M. et al. Effect of breed type and sex on the fatty acid composition of subcutaneous and intramuscular of finishing steers and heifers. Journal of Animal Science, v.73, p.3325-3332, 1995. 